\title{
Assessing Coastal Water Quality through an Overall Index
}

\author{
Nguyen Thi The Nguyen ${ }^{1 *}$, Marteen Sevando ${ }^{2}$ \\ ${ }^{1}$ Faculty of Marine and Coastal Engineering, Thuy loi University, Hanoi, Vietnam \\ ${ }^{2}$ Environmental Engineering and Water Technology Department, UN-IHE, Delft, the Netherlands
}

Received: 23 March 2018

Accepted: 7 May 2018

\begin{abstract}
Over the years, water quality indices have been studied and used in many countries. However, research has focused on fresh water more than coastal water. For coastal countries, the coastal water quality index (WQI) is an important tool for coastal environmental management. This study presents the development of a WQI for coastal waters. A group of 20 scientists were asked to select representative parameters and their importance in the marine environment. The sub-index of each selected variable was developed based on coastal water quality criteria of different countries, and requirements of water quality for coral reefs and seabed grass. After analyzing the eclipsing and ambiguous effects, and the sensitivity of four aggregation methods, the weighted geometric mean function was used to integrate sub-indices of 8 parameters, including total suspended solids (0.18), oil and grease (0.18), total nitrogen or ammonia (0.12), total phosphorus or phosphate (0.12), chlorophyll-a (0.11), chemical oxygen demand (0.11), total coliforms or fecal coliforms (0.09), and saturated oxygen percentage (0.08). The weights of the parameter are given in parentheses. The normal weighted geometric mean function has been modified so that it could be applied in cases of lacking data. The application of the developed index for the coastal zone of Vietnam showed that it accurately reflected the state of water quality in 2017.
\end{abstract}

Keywords: overall assessment, coastal water, WQI, weighted geometric mean

\section{Introduction}

In 1965, Horton (USA) proposed the first formula with the idea of using an index to gather the data needed to assess surface water quality [1]. So far, the water quality index (WQI) has been studied and used in many countries. The purpose of WQI is to turn complex water quality data into information that is understandable and usable by the public. Water quality indices can be used

*e-mail: nguyen.n.t@tlu.edu.vn for overall water quality assessment or for specific use. For specific assessment, the classification of water is on the basis of the type of consumption and application, for example drinking, ecosystem preservation, recreation, irrigation, and livestock [2]. Methods of calculating WQI are diverse, and can be summarized as follows:

WQI for surface and ground waters:

- The method of US National Sanitation Foundation WQI (NSF-WQI): This method uses a non-weighted, weighted arithmetic mean, or geometric mean. The formulas of these indices are shown in Equations 1 and 2. This method has been used extensively in many studies on WQI, for example in studies 
by Naubi et al. [3], Khalik et al. [4], Bora et al. [5], Roy et al. [6], and Ewaid et al. [7]. Besides directed applications, it has been modified into many different forms [8-10]. The advantages of this approach are that the calculation is not too complicated, and produces reasonable results for multi-purpose water sources. The limitation of this approach is its use of a limited number of water quality parameters, namely temperature, turbidity, total solids, dissolved oxygen, bio-chemical oxygen demand, $\mathrm{pH}$, nitrate, phosphate, and fecal coliforms [11]. The other main drawback of the NSF-WQI is the eclipsing effect [2]. Due to this effect, the arithmetic mean has been improved to the Solway form (see Eq. 4), which has been used to assess the quality of water supply in Thailand [12], estuarine water in South Africa, and in a number of surface water studies [13].

- The method of Canadian WQI: This approach uses three criteria to ascertain the level of water pollution: the first is the scope of exceedance (F1), the second is the frequency of exceedance (F2), and the third is the amplitude of exceedance (F3) [11]. This method has also been used in many studies [11, 14, 15]. The advantages of this approach are that it does not limit the number of calculation parameters, and can be used for different water purposes (drinking, recreation, irrigation, etc.) and different water resources (surface, ground, or coastal waters). The limitations of this method are that it does not specify the weight of each parameter, and the F1 value has a strong effect on the results of the WQI calculation [16]. Moreover, there is a lack of guidelines for selecting the optimal parameters for the purposes of use [16].

- Other methods: Rubio-Arias et al. (2013) developed a WQI of an artificial aquatic ecosystem in Mexico by assigning a specific weight in a range of 1 to 4 according to the level of importance of the parameter, and tolerance $\mathrm{Pi}=1$ or 2 to the variables with values in or outside the ideal ranges correspondingly [17]. According to the WQI by Ho (2012), the weights of the parameters are theoretically calculated, based on national environmental standards for different water uses [18]. The fuzzy logic method was applied to calculate the WQI in some studies in Malaysia, China, and India [19, 20].

WQI for coastal and marine waters:

- The research and applications of WQI for coastal water are not as many as those of surface or ground water. In 2012, the U.S. Environmental Protection Agency assessed coastal water quality by applying an index based on percentage of water quality parameters that were in good or poor condition [21]. Darko et al. (2013) used the Solway form to calculate WQI for coastal waters in Ghana [22]. Nguyen et al. (2013) proposed a modified geometric WQI for $\mathrm{Ha}$ Long Bay, Vietnam [23].
- It can be seen that studies on WQI have focused more on surface water [2] and groundwater than on coastal and sea waters. However, for coastal countries, coastal water is one of the most valuable resources. Most socio-economic development activities are concentrated in the coastal zone, which is rich of natural resources and easily accessible. Therefore, the risk of environmental pollution in coastal areas is high. This paper presents an approach to develop a WQI for coastal water to serve the management and protection of marine resources and the environment. The WQI would provide a convenient way for evaluating the water quality of the coastal zone for marine ecosystem protection and human contact, and comparing water quality among different areas of the coast. The methodology for establishing the WQI of the United States was applied in this study.

\section{Materials and Methods}

\section{Selection of Water Quality Parameters, their Weights, and Sub-Indices}

The parameter selection would have more impact on WQI values than the number of parameters [24]. Including many parameters, with few exceedances of guidelines, will increase the WQI value for a site. A review of studies related to coastal water showed that the following parameters were normally used: total suspended solids (TSS), oil and grease, chemical oxygen demand (COD), total nitrogen (TN), ammonia $\left(\mathrm{NH}_{4}^{+}\right)$, total phosphorus (TP), phosphate $\left(\mathrm{PO}_{4}^{3-}\right)$, chlorophyll-a (Chl-a), total coliforms (T. Coli), fecal coliforms (F. Coli), saturated oxygen percentage $\left(\% \mathrm{DO}_{\text {sat }}\right)$, and total organic carbon (TOC). Based on this selection, a group of 20 marine environment scientists in Vietnam and the Netherlands was requested to select parameters for possible inclusion in the index. They were free to add to the list any parameter of their choice. The panelists were also asked to rank the parameters according to their significance as a contributor to overall quality. The rating was done on a scale of 1 (highest) to 3 (lowest). Subsequently, the arithmetic means of the significance ratings were calculated. To convert the rating into weights, a temporary number of 1 was assigned to the parameter that received the highest sum of significance rating. All other temporary weights were developed by dividing the highest sum of significance rating by the sum of significance rating of individual parameters. Then, weighs for each parameter were defined as the ratio of the temporary weight to the sum of temporary weights [12].

The sub-indices are scaled from 1 to 100 , which represent the poorest and the highest water qualities, respectively. The development of the sub-index of 
each selected variable was based on the following information: 1) marine and coastal water quality standards and criteria of the ASEAN, Thailand, Indonesia, Vietnam, Japan, Australia, and the Netherlands; and 2) requirements of water quality for coral reefs and seabed grass.

\section{Selecting theAggregation Function}

Four types of functions were considered in this study: the weighted Solway function (Eq. 1), the weighted arithmetic mean function (Eq. 2), the weighted geometric function (Eq. 3), and the weighted harmonic mean function (Eq. 4). These are popular aggregated methods applied across much WQI research.

$$
\begin{gathered}
W Q I=\sum_{1}^{n} w_{i} q_{i} \\
W Q I=\prod_{1}^{n} q_{i}^{w_{i}} \\
W Q I=\sqrt{\frac{1}{\sum_{i=1}^{n} \frac{w i}{q_{i}^{2}}}} \\
W Q I=\frac{1}{100}\left(\sum_{1}^{n} w_{i} q_{i}\right)^{2}
\end{gathered}
$$

...where " $\mathrm{w}_{\mathrm{i}}$ " and " $\mathrm{q}_{\mathrm{i}}$ " are correspondingly the final weight and the sub-index of parameter " $i$ ".

The above aggregated methods were calculated with the selected parameters and their assigned weights. To assess the eclipsing and ambiguous effects, the subindices were changed in the variable scale (from 1 to 100 ), corresponding to 3 ranges of " $\mathrm{q}_{i}$ " (Bad range: $1 \leq \mathrm{q}_{\mathrm{i}}<34$; medium range $34 \leq \mathrm{q}_{\mathrm{i}}<67$; and good range $68 \leq \mathrm{q}_{\mathrm{i}}<100$ ). The sensitivity of the aggregated methods was also examined during this process.

\section{Water Quality Classification and Range Scales}

The classification scale was determined based on the level and number of the parameters violating the allowable limits (Table 1). WQI values are divided into 5 ranges: excellent, good, medium, bad, and very bad.

\section{Verifying the Constructed WQI}

The constructed index was applied to assess the quality of coastal water in Vietnam. This process also aims to verify the accuracy of the index. At present, the government of Vietnam implements water quality monitoring at 140 locations along the coast during the dry season (April) and rainy season (July or August) at both surface and bottom layers. Therefore, there are 560 data series on coastal water quality per year. Monitoring data showed that water quality did not differ much between dry and wet seasons (except for TSS parameter), and between surface and bottom layers [25]. Consequently, the average concentration values of the selected parameters of each of the 28 coastal provinces/cities, and the 560 data series on coastal water quality in 2017 were used in this process.

\section{Results and Discussion}

\section{Selecting Water Quality Parameters, their Weights and Sub-Indices}

Table 2 shows the selected water quality parameters for the coastal area and their weights. Eight water quality parameters were chosen, including TSS, oil and grease, COD, TN, TP, Chl-a, T. Coli, and \%DO ${ }_{\text {sat }}$. Parameters TN, TP, and T. Coli can be replaced by

\begin{tabular}{|c|c|}
\hline Threshold & States of parameters in comparison with allowance in the standards on coastal water quality and others \\
\hline Upper limit & 100 \\
\hline Excellent & From good threshold to 100 . \\
\hline Good & $\begin{array}{l}\text { One water quality parameter exceeds the allowance for aquaculture and aquatic conservation } \\
\qquad\left(\mathrm{q}_{\mathrm{i}}=67\right) \text { or } \mathrm{q}_{\mathrm{i}} \min \geq 67\end{array}$ \\
\hline Medium & $\begin{array}{l}\text { One water quality parameter exceeds the allowance for beach or areas for recreation activities with directed water } \\
\text { contact }\left(\mathrm{q}_{\mathrm{i}}=34\right)\end{array}$ \\
\hline Bad & $\begin{array}{l}\text { One water quality parameter exceeds the allowance for "other areas" like ports and industrial areas } \\
\qquad\left(\mathrm{q}_{\mathrm{i}}=1\right)\end{array}$ \\
\hline Very bad & $\begin{array}{l}\text { Two water quality parameters exceed the allowance for "other areas" like ports and industrial areas } \\
\qquad\left(\mathrm{q}_{\mathrm{i}}=1\right)\end{array}$ \\
\hline Lower limit & 1 \\
\hline
\end{tabular}
$\mathrm{NH}_{4}^{+}, \mathrm{PO}_{4}^{3-}$, and F. Coli correspondingly. As can be seen in Table 2, most of the scientists questioned in

Table 1 . Thresholds of water quality classification. 
Table 2. Selected parameters for the WQI in the coastal zone and their weights.

\begin{tabular}{|c|c|c|c|}
\hline Parameter & $\begin{array}{c}\text { Significance } \\
\text { rating }\end{array}$ & $\begin{array}{c}\text { Temporary } \\
\text { weight }\end{array}$ & $\begin{array}{c}\text { Final } \\
\text { weight }\end{array}$ \\
\hline Oil and grease & 24 & 2.3 & 0.18 \\
\hline $\mathrm{TSS}$ & 24 & 2.3 & 0.18 \\
\hline $\mathrm{TN}\left({\text { or } \mathrm{NH}_{4}^{+}}^{+}\right)$ & 35 & 1.6 & 0.12 \\
\hline $\mathrm{TP}\left({\text { or } \mathrm{PO}_{4}^{3-}}^{3-}\right.$ & 35 & 1.6 & 0.12 \\
\hline $\mathrm{Chl}_{-\mathrm{a}}$ & 40 & 1.4 & 0.11 \\
\hline $\mathrm{COD}$ & 38 & 1.4 & 0.11 \\
\hline T. Coli (or F. Coli) & 50 & 1.1 & 0.09 \\
\hline \%DO & 55 & 1 & 0.08 \\
\hline
\end{tabular}

Note: TSS: Total suspended solids, TN: Total nitrogen,

$\mathrm{NH}_{4}^{+}$: Ammonia, TP: Total phosphorus, $\mathrm{PO}_{4}^{3--}$ : Phosphate,

Chl-a: Chlorophyll-a, COD: Chemical oxygen demand,

T. Coli: Total coliforms, F. Coli: Fecal coliforms,

and $\% \mathrm{DO}_{\text {sat }}$ : Saturated oxygen percentage

this study agreed that TSS and oil and grease were direct toxic stressors to coastal resources and habitats, so they were the most important parameters. This finding also is stated in the report of PEMSEA [26]. COD, TN, TP, and Chl-a are not toxic but can directly affect ecosystems and biota [27]. Total coliforms (or fecal coliforms) are an important parameter that needs to be considered in recreational waters because it is toxic to human beings [27]. Lastly, saturated oxygen content affects the process of respiration of marine biota. Low dissolved oxygen concentration has an adverse effect on many aquatic organisms (e.g. fish, invertebrates, and microorganisms) that depend on oxygen dissolved in the water for efficient functioning [27]. Sub-indices of each parameter are shown in Table 3.

\section{Aggregation Function}

The results of the WQI calculations with the four methods of aggregation when the sub-index values were varied in their ranges are presented in Table 4. It can be seen that the eclipsing effect of the weighted arithmetic is evident in the data series 8,12 , and 16 to 20. For example, in data series 8 , while the sub-index of a parameter is very low $\left(\mathrm{q}_{\mathrm{i}}=1\right)$, the weighted arithmetic still gives a higher overall WQI compared to other methods. The result of this calculation is not reasonable.

The ambiguity is clearly expressed in the weighted harmonic mean, and the Solway where the WQI results of those methods usually tend to lower sub-indices. In the data series 2, 3, and 4, the results of the Solway are lower than the sub-indices. For example, in the second data series, while all sub-indices are 67, the final WQI value is 45 . This is unreasonable.

The WQI results calculated by the weighted harmonic mean in data series $8,12,16$, and 17 to 20 are also relatively low as compared to the sub-indices. These reveal that the ambiguity of the weighted harmonic mean is slightly high. In addition, the sensitivity of this method is very low in the series of data 17 to 20 . In these data series, the sub-index of TSS varies from 1 to 100 but the WQI results remain at 2 .

The eclipsing and ambiguous effects of the weighted geometry are lower than those of the Solway and the weighted harmonic mean. When the sub-index values differ widely, the final result of this method tends to favor the smallest sub-index values rather than the weighted arithmetic (for example in the data series 8 , 12 , and 16 to 20 ).

From the results of the calculations and analysis above, it can be concluded that the weighted arithmetic is not ambiguous but highly eclipsing. This main drawback of the weighted arithmetic, which is applied in the NSF-WQI, was mentioned in the study by Tirkey

Table 3. Sub-index values (qi).

\begin{tabular}{|c|c|c|c|c|c|c|c|}
\hline \multirow{3}{*}{$\mathrm{i}$} & \multirow{3}{*}{$\mathrm{q}_{\mathrm{i}}$} & \multicolumn{6}{|c|}{ Concentration values $\left(\mathrm{C}_{\mathrm{i}}\right)$ for each parameter } \\
\hline & & COD & \multirow{2}{*}{$\% \mathrm{DO}_{\text {sat }}$} & \multirow{2}{*}{$\begin{array}{l}\text { Oil and grease } \\
(\mathrm{mg} / \mathrm{L})\end{array}$} & $\mathrm{TN}$ & $\mathrm{TP}$ & $\mathrm{PO}_{4}^{3-}-\mathrm{P}$ \\
\hline & & $\left(\mathrm{mgO}_{2} / \mathrm{L}\right)$ & & & $(\mathrm{mgN} / \mathrm{L})$ & $(\mathrm{mgP} / \mathrm{L})$ & $(\mathrm{mg} / \mathrm{L})$ \\
\hline 1 & 100 & $\leq 3$ & 100 & 0 & $\leq 0.25$ & $\leq 0.02$ & $\leq 0.015$ \\
\hline 2 & 67 & 4 & 65 or 140 & 0.1 & 0.35 & 0.05 & 0.045 \\
\hline 3 & 34 & 25 & 40 & 0.2 & 0.75 & 0.5 & 0.08 \\
\hline 4 & 1 & $>50$ & 20 & $>0.3$ & $>1.5$ & $>1$ & $>0.5$ \\
\hline \multirow{2}{*}{$\mathrm{i}$} & \multirow{2}{*}{$\mathrm{q}_{\mathrm{i}}$} & $\mathrm{NH}_{4}^{+}-\mathrm{N}$ & Chl-a & T. Coli & \multirow{2}{*}{$\begin{array}{c}\text { F. Coli } \\
\text { (F.Coli/100mL) }\end{array}$} & TSS & \\
\hline & & $(\mathrm{mg} / \mathrm{L})$ & $(\mu \mathrm{g} / \mathrm{L})$ & $(\mathrm{MPN} / 100 \mathrm{~mL})$ & & $(\mathrm{mg} / \mathrm{L})$ & \\
\hline 1 & 100 & $\leq 0.1$ & $\leq 1.4$ & $\leq 500$ & $\leq 100$ & $\leq 20$ & \\
\hline 2 & 67 & 0.3 & 3 & 1000 & - & 50 & \\
\hline 3 & 34 & 0.5 & 10 & - & 500 & - & \\
\hline 4 & 1 & $>1$ & $>20$ & $>2000$ & $>1000$ & $>100$ & \\
\hline
\end{tabular}


Table 4. Summary of WQI calculation results with differently aggregated methods

\begin{tabular}{|c|c|c|c|c|c|c|c|c|c|c|c|c|}
\hline \multirow{2}{*}{ No. } & \multicolumn{8}{|c|}{ Sub-index } & \multirow{2}{*}{$\begin{array}{l}\text { Weighted } \\
\text { geometric }\end{array}$} & \multirow{2}{*}{$\begin{array}{l}\text { Weighted } \\
\text { arithmetic }\end{array}$} & \multirow{2}{*}{ Solway } & \multirow{2}{*}{$\begin{array}{c}\text { Weighted } \\
\text { harmonic } \\
\text { mean }\end{array}$} \\
\hline & $\begin{array}{l}\text { Oil and } \\
\text { grease }\end{array}$ & TSS & COD & $\mathrm{TP}$ & $\mathrm{TN}$ & Chl-a & $\% \mathrm{DO}_{\text {sat }}$ & T.Coli & & & & \\
\hline 1 & 100 & 100 & 100 & 100 & 100 & 100 & 100 & 100 & 100 & 100 & 100 & 100 \\
\hline 2 & 67 & 67 & 67 & 67 & 67 & 67 & 67 & 67 & 67 & 67 & 45 & 67 \\
\hline 3 & 34 & 34 & 34 & 34 & 34 & 34 & 34 & 34 & 34 & 34 & 12 & 34 \\
\hline 4 & 1 & 1 & 1 & 1 & 1 & 1 & 1 & 1 & 1 & 1 & 0 & 1 \\
\hline 5 & 100 & 100 & 100 & 100 & 100 & 100 & 100 & 100 & 100 & 100 & 100 & 100 \\
\hline 6 & 67 & 100 & 100 & 100 & 100 & 100 & 100 & 100 & 94 & 95 & 89 & 91 \\
\hline 7 & 34 & 100 & 100 & 100 & 100 & 100 & 100 & 100 & 84 & 89 & 79 & 66 \\
\hline 8 & 1 & 100 & 100 & 100 & 100 & 100 & 100 & 100 & 47 & 84 & 70 & 2 \\
\hline 9 & 67 & 100 & 100 & 100 & 100 & 100 & 100 & 100 & 94 & 95 & 89 & 91 \\
\hline 10 & 67 & 67 & 100 & 100 & 100 & 100 & 100 & 100 & 88 & 89 & 79 & 84 \\
\hline 11 & 67 & 34 & 100 & 100 & 100 & 100 & 100 & 100 & 78 & 84 & 70 & 64 \\
\hline 12 & 67 & 1 & 100 & 100 & 100 & 100 & 100 & 100 & 44 & 78 & 61 & 2 \\
\hline 13 & 34 & 100 & 100 & 100 & 100 & 100 & 100 & 100 & 84 & 89 & 79 & 66 \\
\hline 14 & 34 & 67 & 100 & 100 & 100 & 100 & 100 & 100 & 78 & 84 & 70 & 64 \\
\hline 15 & 34 & 34 & 100 & 100 & 100 & 100 & 100 & 100 & 70 & 78 & 61 & 53 \\
\hline 16 & 34 & 1 & 100 & 100 & 100 & 100 & 100 & 100 & 39 & 73 & 53 & 2 \\
\hline 17 & 1 & 100 & 100 & 100 & 100 & 100 & 100 & 100 & 47 & 84 & 70 & 2 \\
\hline 18 & 1 & 67 & 100 & 100 & 100 & 100 & 100 & 100 & 44 & 78 & 61 & 2 \\
\hline 19 & 1 & 34 & 100 & 100 & 100 & 100 & 100 & 100 & 39 & 73 & 53 & 2 \\
\hline 20 & 1 & 1 & 100 & 100 & 100 & 100 & 100 & 100 & 22 & 67 & 45 & 2 \\
\hline
\end{tabular}

(2015) [2]. Due to this effect, the weighted arithmetic does not properly reflect the pollution level in many cases. The weighted harmonic mean, and the Solway forms are ambiguous, and therefore they sometimes give unreasonable results. The sensitivity of the weighted harmonic mean is low. Consequently, the weighted geometric function is the most optimal. With the selected parameters, and their assigned weights, it has lower ambiguity, eclipsing effects and high sensitivity. In addition, the application of this method is relatively easier than the weighted harmonic mean, or the Solway. Gupta (2003) also stated that the multiplicative index was the most suitable for coastal waters [28]. When water quality parameters have different weights, the multiplicative index is changed to a weighted geometric one.

The normal form of WQI based on the weighted geometric function is shown in Equation 2. However, in the cases of lacking one or two data of selected parameters due to unrespectable reasons, Equation (2) will not give an accurate result of actual water quality. This is caused by the lack of contributions of missing

Table 5. The results of WQI with the normal and modified weighted geometric forms.

\begin{tabular}{|c|c|c|c|c|c|c|c|c|c|c|}
\hline \multirow{3}{*}{$\begin{array}{l}\text { Case of } \\
\text { missing data }\end{array}$} & \multicolumn{8}{|c|}{ Sub-index } & \multirow{3}{*}{$\left(\prod^{n} q_{i}^{w_{i}}\right)$} & \multirow{3}{*}{$\left(\prod_{i}^{n-m} q_{i}^{w_{i}}\right)^{1, \sum_{1}^{1, m} w_{i}}$} \\
\hline & $\begin{array}{l}\text { Oil and } \\
\text { grease }\end{array}$ & TSS & $\mathrm{TN}$ & $\mathrm{TP}$ & Chl-a & COD & T.coli & $\% \mathrm{DO}_{\text {sat }}$ & & \\
\hline & 0.18 & 0.18 & 0.12 & 0.12 & 0.11 & 0.11 & 0.09 & 0.08 & & \\
\hline None & 100 & 100 & 100 & 100 & 100 & 100 & 100 & 100 & 100 & 100 \\
\hline$\% \mathrm{DO}_{\text {sat }}$ & 100 & 100 & 100 & 100 & 100 & 100 & 100 & - & 69 & 100 \\
\hline T.Coli & 100 & 100 & 100 & 100 & 100 & 100 & - & 100 & 66 & 100 \\
\hline COD & 100 & 100 & 100 & 100 & 100 & - & 100 & 100 & 60 & 100 \\
\hline
\end{tabular}


Table 6. Coastal water quality classification and use.

\begin{tabular}{|c|c|c|c|}
\hline No. & CoWQI & Water quality & Beneficial uses \\
\hline 1 & $97-100$ & Excellent & Can be used for any purpose \\
\hline 2 & $92-96$ & Good & Can be used for any purpose except the protection of aquatic life or special aquaculture \\
\hline 3 & $70-91$ & Medium & Tourism, recreation without direct water contact, ports and navigation, industrial water supply \\
\hline 4 & $50-69$ & Bad & $\begin{array}{c}\text { Ports and navigation, industrial water supply or other purposes that do not need high water } \\
\text { quality }\end{array}$ \\
\hline 5 & $1-50$ & Very bad & Ports and navigation only \\
\hline
\end{tabular}

parameters. Consequently, the sum of weights is now less than 1. Therefore, Equation 2 should be corrected so that it can reasonably describe the water quality in the cases of missing data. The total weight of the parameters must be equal to 1 in all cases. Mathematically, it should be multiplied by the inverse of the total weight of the present parameters. Thus, the weighted geometric form in Equation 2 is modified as follows:

$$
\text { CoWQI }=\left(\prod_{1}^{n-m} q_{i}^{w_{i}}\right)^{1 / \sum_{1}^{n-m} w_{i}}
$$

...where " $\mathrm{q}_{\mathrm{i}}$ " and " $\mathrm{w}_{\mathrm{i}}$ " are the sub-index and weight of the present parameter $\mathrm{i}, \mathrm{n}$ is the number of the selected parameters for WQI calculation ( $\mathrm{n}=8$ in this study), and $\mathrm{m}$ is the number of missing parameters.

When there are enough parameters selected, the values of the terms in Equation 5 are as follows: $\mathrm{n}=8$, $\mathrm{m}=0$, and $\sum_{1}^{\mathrm{n}-\mathrm{m}} \mathrm{w}_{\mathrm{i}}=1$. Thus Equation 5 will convert to the normal weighted geometric form as in Equation 6:

$$
\mathrm{CoWQI}=\prod_{1}^{8} q^{w_{i}}
$$

Or:

CoWQI $=\left(\mathrm{q}_{o i l}^{0.18} * \mathrm{q}_{T S S}^{0.18} * \mathrm{q}_{T N}^{0.12} * \mathrm{q}_{T P}^{0.12} * \mathrm{q}_{C h l-a}^{0.11} * \mathrm{q}_{C O D}^{0.11} * \mathrm{q}_{T . C o l i}^{0.09} * \mathrm{q}_{\% \text { DO sat }}^{0.08}\right)$

When there are not enough parameters selected, the values of the terms in Equation 5 are: $n=8$, $\mathrm{m} \neq 0$, and $\sum_{1}^{\mathrm{n}-\mathrm{m}} \mathrm{w}_{\mathrm{i}}<1$. Therefore, the total weight of the parameters has to be revised so that it is equal to 1. This correction is made by multiplying the exponent $\left(1 / \sum_{1}^{n-m} W_{i}\right)$ to the final result of the WQI. Two examples of how to calculate the correction according to Equation 5 are as follows:

Example 1: Missing $\% \mathrm{DO}_{\text {sat }}$. Then, $\mathrm{n}=8, \mathrm{~m}=1$, and $\sum_{i}^{n-m} \mathrm{~W}_{\mathrm{i}}=0.92$. The resulting WQI should be corrected with an exponent of (1/0.92) as follows:

$$
\text { CoWQI }=\left(\mathrm{q}_{o i l}^{0.18} * \mathrm{q}_{T S S}^{0.18} * \mathrm{q}_{T N}^{0.12} * \mathrm{q}_{T P}^{0.12} * \mathrm{q}_{C h l-a}^{0.11} * \mathrm{q}_{C O D}^{0.11} * \mathrm{q}_{T . C o l i}^{0.09}\right)^{(1 / 0.92)}
$$

Example 2: Missing \% $\mathrm{DO}_{\text {sat }}$, and T. Coli. Then, $\mathrm{n}=8, \mathrm{~m}=2$, and $\sum^{\mathrm{n}-\mathrm{m}} \mathrm{w}_{\mathrm{i}}=0.83$, the resulting WQI should be corrected with an exponent of $(1 / 0.83)$ as follows:

$$
\text { CoWQI }=\left(\mathrm{q}_{\text {oil }}^{0.18} * \mathrm{q}_{T S S}^{0.18} * \mathrm{q}_{T N}^{0.12} * \mathrm{q}_{T P}^{0.12} * \mathrm{q}_{C h l-a}^{0.11} * \mathrm{q}_{C O D}^{0.11}\right)^{(1 / 0.83)}
$$

Table 5 gives examples of the WQI calculated by the normal and modified weighted geometric forms. In the case of all selected parameters that are available, and sub-indices of these parameters are equal to 100 ,

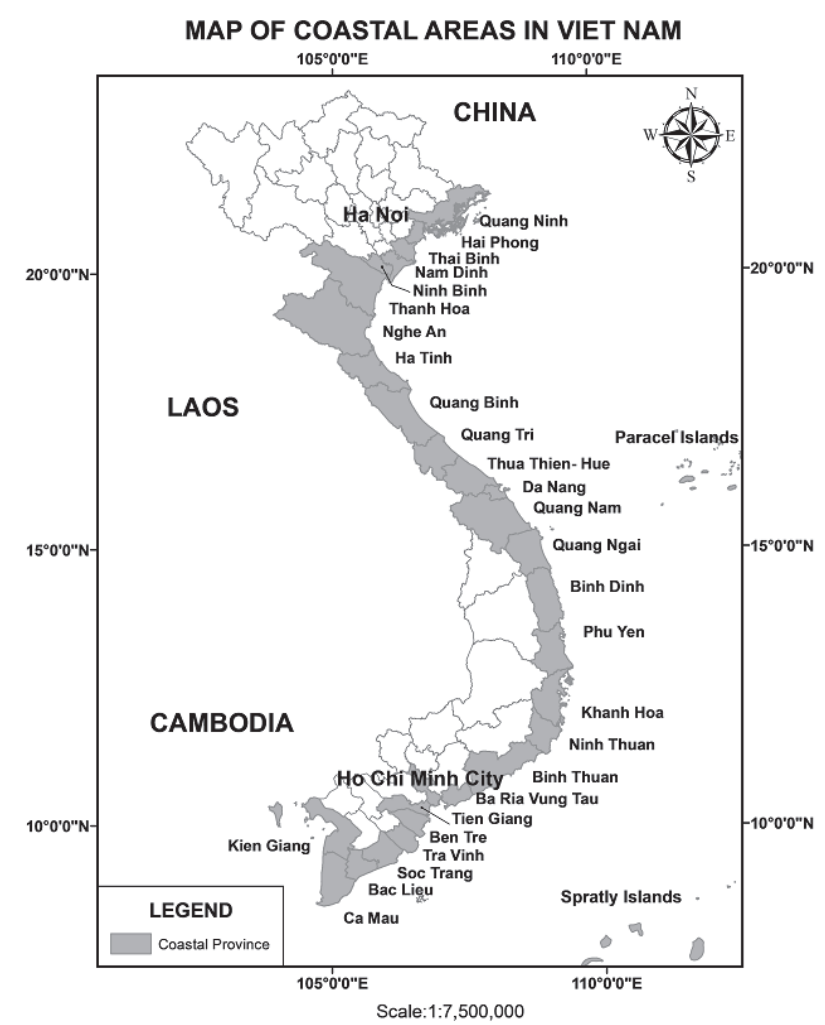

Fig. 1. Map of the coastal zone in Vietnam. 
Table 7. Average concentrations of the selected parameters at each coastal province in Vietnam in 2017.

\begin{tabular}{|c|c|c|c|c|c|c|c|c|c|}
\hline Coastal province & Symbol & COD & $\% \mathrm{DO}_{\text {sat }}$ & $\begin{array}{l}\text { Oil and } \\
\text { grease }\end{array}$ & $\mathrm{TN}$ & TP & Chl-a & T.Coli & TSS \\
\hline Quang Ninh & L1 & 3.0 & 100 & 0.17 & 0.20 & 0.030 & 8.52 & 27.5 & 32.5 \\
\hline Hai Phong & $\mathrm{L} 2$ & 3.3 & 100 & 0.48 & 0.15 & 0.020 & 1.40 & 1000.0 & 40.0 \\
\hline Thai Binh & L3 & 1.9 & 100 & - & 0.25 & 0.024 & 1.40 & - & 75.0 \\
\hline Nam Dinh & L4 & 2.6 & 100 & - & 0.10 & 0.021 & 1.35 & - & 72.5 \\
\hline Ninh Binh & L5 & 2.0 & 100 & - & 0.09 & 0.018 & 1.78 & 177.0 & 24.5 \\
\hline Thanh Hoa & L6 & 3.0 & 100 & - & 0.25 & 0.022 & 3.72 & 442.0 & 25.0 \\
\hline Nghe An & L7 & 1.1 & 100 & 0.05 & 0.12 & 0.020 & 5.69 & 47.0 & 56.0 \\
\hline Ha Tinh & L8 & 2.3 & 67 & 0.15 & 0.45 & 0.053 & 2.88 & 385.0 & 17.5 \\
\hline Quang Binh & L9 & 1.9 & 80 & 0.10 & 0.17 & 0.023 & 2.75 & 25.5 & 8.5 \\
\hline Quang Tri & L10 & 2.3 & 100 & 0.20 & 0.10 & 0.021 & 8.72 & 18.5 & 14.0 \\
\hline Thua Thien Hue & L11 & 3.7 & 100 & 0.07 & 0.20 & 0.035 & 1.75 & 108.0 & 35.0 \\
\hline Da Nang & L12 & 2.4 & 100 & 0.20 & 0.15 & 0.032 & 1.75 & - & 45.0 \\
\hline Quang Nam & L13 & 3.1 & 100 & 0.20 & 0.19 & 0.041 & 0.75 & 35.0 & 30.0 \\
\hline Quang Ngai & L14 & 3.5 & 100 & 0.19 & 0.16 & 0.032 & 1.32 & 30.0 & 30.0 \\
\hline Binh Dinh & L15 & 2.3 & 100 & 0.21 & 0.11 & 0.028 & 1.85 & - & 30.0 \\
\hline Phu Yen & L16 & 1.3 & 100 & - & 0.07 & 0.010 & 0.71 & - & 7.5 \\
\hline Khanh Hoa & L17 & 2.3 & 100 & - & 0.06 & 0.017 & 0.77 & - & 11.5 \\
\hline Ninh Thuan & L18 & 1.2 & 100 & - & 0.05 & -1 & 0.75 & - & 3.5 \\
\hline Binh Thuan & L19 & 1.4 & 100 & 0.10 & 0.15 & 0.022 & 0.71 & - & 3.5 \\
\hline Ba Ria-Vung Tau & L20 & 4.1 & 100 & 0.20 & 0.25 & 0.042 & 1.15 & 39.5 & 6.0 \\
\hline Ho Chi Minh City & L21 & 3.2 & 100 & 0.19 & 0.18 & 0.020 & 6.98 & 66.5 & 58.0 \\
\hline Tien Giang & L22 & 1.9 & 100 & - & 0.33 & 0.021 & 1.75 & - & 11.0 \\
\hline Ben Tre & L23 & 2.2 & 100 & - & 0.08 & 0.017 & 2.00 & - & 10.5 \\
\hline Tra Vinh & L24 & 2.9 & 100 & - & 0.12 & 0.030 & 1.65 & 178.0 & 10.5 \\
\hline Soc Trang & L25 & 2.4 & 100 & - & 0.25 & 0.035 & 0.75 & - & 3.0 \\
\hline Bac Lieu & L26 & 2.0 & 100 & - & 0.20 & 0.014 & 0.62 & 230.0 & 28.5 \\
\hline $\mathrm{Ca} \mathrm{Mau}$ & L27 & 2.9 & 100 & - & 0.15 & 0.020 & 0.02 & 203.5 & 17.0 \\
\hline Kien Giang & L28 & 2.4 & 100 & - & 0.11 & 0.020 & 0.37 & 35.0 & 9.0 \\
\hline
\end{tabular}

Unit: COD: $\mathrm{mgO}_{2} / \mathrm{L}$; oil and grease: $\mathrm{mg} / \mathrm{L}$; TN: mgN/L, TP: mgP/L, Chl-a: $\mu \mathrm{g} / \mathrm{L}$, T. Coli: MNP/100mL and TSS: mg/L. Note: "-" means "below detection"

Data source: MONRE, 2017 [29]

the WQI is calculated by the normal geometric form (Eq. 7) of 100, which is logical. However, if there is a lack of data for $\% \mathrm{DO}_{\text {sat }}$ or COD or TOC or oil and grease, the WQI result is not equal to 100 when all sub-indices are 100. This is unreasonable. However, the modified weighted geometric form (Eq. 5) gives accurate results.

It should be noted that with the lack of data, the WQI results will not accurately reflect the state of water quality. When the missing parameters have small weights, the WQI results may be relatively reasonable. However, when the missing parameters have high weights, the WQI results may not be accurate, and will not reflect the state of water quality correctly.

\section{Water Quality Classification and Range Scales}

The final results of water quality classification are summarized in Table 6. 


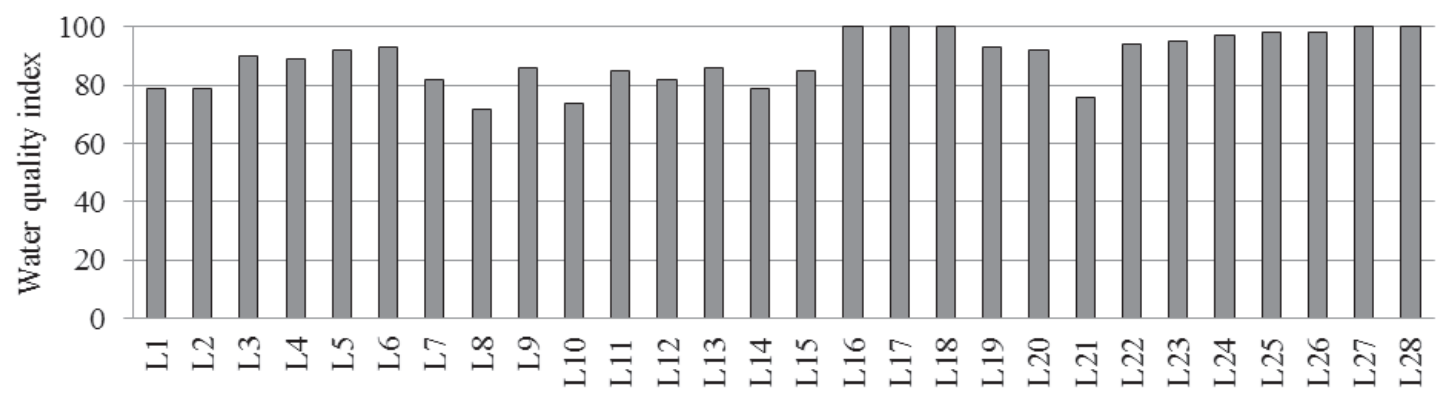

Coastal provinces (from the North to the South)

Fig. 2. Water quality index in different coastal provinces in Vietnam.

\begin{tabular}{|c|c|c|c|c|c|c|c|}
\hline L1: & Quang Ninh & L8 $:$ & Ha Tinh & L15: & Binh Dinh & L22: & Tien Giang \\
\hline L2: & Hai Phong & L9 $:$ & Quang Binh & L16: & Phu Yen & L23: & Ben Tre \\
\hline L3: & Thai Binh & L10: & Quang Tri & L17: & Khanh Hoa & L24: & Tra Vinh \\
\hline L4: & Nam Dinh & L11: & Thua Thien Hue & L18: & Ninh Thuan & L25: & Soc Trang \\
\hline L5: & Ninh Binh & L12: & Da Nang & L19: & Binh Thuan & L26: & Bac Lieu \\
\hline L6: & Thanh Hoa & L13: & Quang Nam & L20: & Ba Ria-Vung Tau & L27: & Ca Mau \\
\hline L7: & Nghe An & L14: & Quang Ngai & L21: & Ho Chi Minh City & L28: & Kien Giang \\
\hline
\end{tabular}

\section{Verifying the Constructed WQI}

Vietnam is a country in Southeast Asia with a long coastline of 3,260 km and about 3,000 islands. There are 28 coastal provinces, and cities in 63 provinces in the country (Fig. 1). Most big, developed cities in Vietnam are located on the coastal zone. The coastal area accounts for $17 \%$ of the total area of the country, and about $25 \%$ of Vietnamese settlements are here. Socio-economic development activities on the coastal areas of Vietnam include industry, agriculture, aquaculture and fishing, tourism and services, maritime and seaports. Recently, marine economic sectors have contributed up to $55 \%$ of the country's GDP. Coastal and sea water quality plays a very important role for biological resources, and the development of marine-based economic sectors. Therefore, protecting these waters is an extremely important task for the Vietnamese government.

The constructed CoWQI was examined with the 560 monitoring data series on 140 locations on the coast of Vietnam, and with the 28 data series of average concentrations of the selected parameters at 28 coastal provinces in 2017. The average concentrations of the selected parameters are presented in Table 7. It can be seen that most of the parameters were within the limitation of the Vietnam national technical regulation on marine water quality. However, due to effects from estuaries and wastes from social-economic activities, some coastal water areas had high levels of TSS (for example of locations L3, L4, L7, and L21). In addition, the increase in organic matter, oil, and grease were also a main concern for the quality of coastal water in Vietnam in recent years. The contents of parameters such as COD, TN, and Chl-a in 2017 in some areas were above the national limitation for aquaculture and bathing sites, especially in the coastal zones of the North and the South. The level of organic pollution in the Northern coastal waters was higher than in the central and southern regions. In fact, red tide appeared in areas such as in Quang Ninh (location L1), Hai Phong (location L2), Ha Tinh (location L8), Khanh Hoa (location L17), Ninh Thuan (location L18), and Binh Thuan (location L19) [25]. The oil and grease contents tended to increase in seaport areas. The seaports in Hai Phong (location L2), Da Nang (location L12), and Ba Ria-Vung Tau (location L20) had oil and grease contents exceeding the national allowable threshold. This was mainly due to the operation of vessels that leached oil and grease on the sea.

The results of the assessment of coastal water quality in Vietnam in 2017 are shown in Fig. 2. The CoWQI results show that the coastal waters of Vietnam were of medium to excellent quality. Eight coastal cities/ provinces had excellent water quality, and the coastal waters were acceptable for any purpose, for example for protection of aquatic life, recreation, aquaculture, and salt production. Most of these cities/provinces were concentrated in the south. Coastal water quality parameters of those cities and provinces were almost below the permissible limits for all purposes; therefore, WQI results were between 97 and 100 . There were 12 of 28 coastal cities, and provinces that had good coastal water quality. The WQI values of these provinces varied from 85 to 95 . These provinces had some water quality parameters that slightly exceeded the permissible limits for aquatic conservation, so that the coastal waters in 
those provinces could be used for any purpose, except for the protection of aquatic life or special aquaculture purposes. For example, locations L3 and L4 had the average concentrations of TSS of 72 and $75 \mathrm{mg} / \mathrm{L}$, respectively, which exceeded the allowable threshold of $50 \mathrm{mg} / \mathrm{L}$ for aquatic life protection. At locations L2 and L19, the contents of TP, oil, and grease also violated the requirement for protection of aquatic life. There were 8 of 28 coastal cities and provinces that had medium coastal quality with a WQI range from 72 to 82 . This was due to the contents of oil and grease, and other parameters did not meet the requirement for protection of aquatic life or direct water contact. This can be seen on locations L8, L10, L21, L1, L2, L14, L7, and L12. Therefore, those coastal waters can be used for tourism, recreation (without direct water contact), ports, navigation, and industrial water supply. There were no provinces that had bad or very bad coastal waters.

Based on the application of the CoWQI on the assessment of coastal water in Vietnam in 2017, it can be concluded that the CoWQI gives reasonable results, and reflects well the status of coastal water quality. Still, it needs more testing with other coastal countries.

\section{Conclusions}

In this study, a WQI has been built in accordance with the nature of the coastal zones in the ASEAN, Japan, Australia, the Netherlands, and the requirements of water quality for coral reefs and seabed grass. The weighted geometric mean function was used to integrate sub-indices of 8 parameters, including TSS $(0.18)$, oil and grease $(0.18), \mathrm{TN}$ or $\mathrm{NH}_{4}^{+}(0.12)$, TP or $\mathrm{PO}_{4}^{3-}(0.12)$, Chl-a (0.11), COD (0.11), total coliforms or feacal coliform (0.09), and $\% \mathrm{DO}_{\text {sat }}(0.08)$. The weights of the parameter are given in parentheses. The normal geometric WQI has been modified so that it is able to access coastal water quality in cases of lacking data. The application of the developed index for the coastal zone of Vietnam showed that it accurately reflected the state of water quality in 2017. The results indicated that most of the Southern coast of Vietnam (8 provinces) had excellent water quality, and could be used for all purposes of water use. Good quality coastal waters were scattered in northern and central Vietnam, including 12 provinces and cities. These waters were acceptable for all socio-economic developmental activities except for aquatic conservation. Eight provinces with average coastal water quality could be used for tourism, recreation (without direct water contact), ports, navigation, and industrial water supply, etc. There were no coastal waters that had bad or very bad quality. It is recommended to check with other data sets of over several years to define the real situation of water quality along the Vietnam coast.

\section{Acknowledgements}

The authors would like to thank the Vietnam Ministry of Natural Resources and Environment for data supporting the study.

\section{Conflict of Interest}

The authors declare no conflict of interest.

\section{References}

1. OTT W.R. Water Quality Indices: A survey of indices used in the United States; Oxford University. U.S., 65, 1978.

2. TIRKEY P., BHATTACHARYA T., CHAKRABORTY S., Water quality indices- Important tools for water quality assessment. International Journal of Advances in Chemistry, 1 (1), 15, 2013.

3. NAUBI I., ZARDARI N.H., SHIRAZI, S.M., IBRAHIM N.F.B., BALOO L. Effectiveness of water quality index for monitoring Malaysian River water quality. Polish Journal of Environmental Studies, 25 (1), 231, 2016.

4. KHALIK W.M.A.W.M., ABDULLAH M.P., AMERUDIN N.A., PADLI N. Physicochemical analysis on water quality status of Bertam River in Cameron highlands, Malaysia. Journal of Materials and Environmental Science, 4 (4), 488, 2013.

5. BORA M., GOSWAMI D.C. Water quality assessment in terms of water quality index (WQI): Case study of the Kolong River, Assam, India. Applied Water Science, 7 (6), 3125, 2016.

6. ROY R., MAJUMDER M., BARMAN R.N. Assessment of water quality by RSM and ANP: A case study in Tripura, India. Asian Journal of Water, Environment and Pollution, 14 (1), 51, 2017.

7. EWAID S.H., ABED S.A. Water quality index for AlGharraf River, Southern Iraq. Egyptian Journal of Aquatic Research, 43 (2), 117, 2017.

8. MORA-OROZCO C.D.L, FLORES-LOPEZ H., RUBIOARIAS H., CHAVEZ-DURAN A., \& OCHOA-RIVERO J. Developing a water quality index (WQI) for an irrigation dam. International Journal of Environmental Research and

9. RUBIO-ARIAS H., CONTRERAS-CARAVEO M., QUINTANA R.M., SAUCEDO-TERAN R.A., PINALESMUNGUIA A. An overall water quality index (WQI) for a man-made aquatic reservoir in Mexico. International Journal of Environmental Research and Public Health, 9 (5), 1687, 2012.

10. CYMES I., GLIŃSKA-LEWCZUK K. The use of water quality indices (WQI and SAR) for multipurpose assessment of water in dam reservoirs. Journal of Elementology, 21 (4), 1211, 2016.

11. NNAJI C.C., MAMA C.N., EKONG C.I., AGU C.C. A comparative evaluation of the water quality standards of different countries. Asian Journal of Water, Environment and Pollution, 13 (2), 15, 2016.

12. PRAKIRAKE C., CHAIPRASERT P., TRIPETCHKUL S. Development of specific water quality index for water supply in Thailand. Songklanakarin Journal Science and Technololy, 31 (1), 91, 2009.

13. HANH P.T.M. Development of water quality indices for surface water quality evaluation in Vietnam; PhD. Thesis, Korea, 67, 2009. 
14. FATAEI E., SEYYEDSHARIFI, S.A., SEIIEDSAFAVIYAN, S.T., Nasrollahzadeh, S. Water quality assessment based on WQI and CWQI indexes in Balikhlou River, Iran. Journal of Basic and Applied Scientific Research, 3 (3), 263, 2013.

15. OKUNLOLA I.A., AMADI A.N., IDRIS-NDA A., AGBASI K., KOLAWOLE. L. L. Assessment of water quality of Gurara water transfer from Gurara dam to lower Usuma dam for Abuja water supply, FCT, Nigeria. American Journal of Water Resources, 2 (4), 74, 2014.

16. ENVIRONMENT CANADA. CCME national water quality index workshop: A path forward for consistent implementation and reporting, November 24-25, 2003. Halifax, Nova Scotia, Canada. Workshop proceedings, 81, 2003.

17. RUBIO-ARIAS H., OCHOA-RIVERO J.M., QUINTANA R.M., SAUCEDO-TERAN R., ORTIZ-DELGADO R.C., REY-BURCIAGA N.I., ESPINOZA-PRIETO J. R. Development of a water quality index (WQI) of an artificial aquatic ecosystem in Mexico. Journal of Environmental Protection, 4, 1296, 2013.

18. HO P.N. Total water quality index using weighting factors and standardized into a parameter. EnvironmentAsia, 5 (2), 63, 2012

19. LI R., ZOU Z., AN Y. Water quality assessment in Qu River based on fuzzy water pollution index method. Journal of Environmental Sciences (China), 50, 87, 2016.

20. RAMAN B.V, REINIER B., MOHAN S. Fuzzy logic water quality index and importance of water quality parameters. Air, Soil and Water Research, 2, 51, 2009.

21. EPA U.S., NOAA. National coastal condition report IV; United State Environmental Protection Agency, U.S, 5, 2012.

22. DARKO H.F., ANSA-ASARE O., PAINTSIL A. A number description of Ghanaian Water Quality - A case study of the Southwestern and coastal rivers systems of Ghana. Journal of Environmental Protection, 4 (11), 1318, 2013.
23. NGUYEN N.T.T, HOI N.C., LOAN D.K. Development of water quality index for coastal zone and application in Ha Long Bay. VNU Journal of Earth and Environmental Sciences, 29 (4), 43, 2013.

24. GARTNER LEE LIMITED. A sensitivity analysis of the Canadian water quality index; A report for the Canadian Council of Ministers of the Environment, Canada, 28, 2006.

25. MINISTRY OF NATURAL RESOURCES AND ENVIRONMENT (MONRE). National report on environmental status on the period 2011-2015; Ministry of Natural Resources and Environment, Hanoi, Vietnam, 96, 2016 [In Vietnamese].

26. PARTNERSHIPS IN ENVIRONMENTAL MANAGEMENT FOR THE SEAS OF EAST ASIA (PEMSEA). Manila Bay: Initial risk assessment. Global Environment Facility/United Nations Development Programme/International Maritime Organization Regional Programme on Building Partnerships in Environmental Management for PEMSEA; Quezon City, Philippines, 93, 2001.

27. AUSTRALIAN AND NEW ZEALAND ENVIRONMENT AND CONSERVATION COUNCIL AGRICULTURE (ANZECC) and AUSTRALIAN RESOURCE MANAGEMENT COUNCIL OF AUSTRALIA AND NEW ZEALAND (ARMCANZ). Australian and New Zealand guidelines for fresh and marine water quality; Canberra, Australia, Volume 1, 3.322, 3.3-25, Volume 2, 8.1-8.12 ( $1^{\text {st }}$ ed. $), 2000$.

28. GUPTA A.K., GUPTA S.K., PATIL R.S. A comparison of water quality indices for coastal water. Journal of Environmental Science and Health. Part A, Toxic/ Hazardous Substances and Environmental Engineering, 38 (11), 2711, 2003.

29. MINISTRY OF NATURAL RESOURCES AND ENVIRONMENT (MONRE). National Report on coastal environment in Vietnam. Hanoi, Vietnam, 40, 2017. 